\title{
PENGARUH PENGGUNAAN ANKLE FOOT ORTHOSIS DINAMIS TERHADAP KECEPATAN JALAN PADA ANAK PENDERITA CEREBRAL PALSY
}

\author{
Cica Trimandasari M, Sri Surini Pudjiastuti, Siti Rokhati \\ Poltekkes Kemenkes Surakarta Jurusan Ortotik Prostetik
}

\begin{abstract}
Background: cerebral palsy is a non-progressive motor disorder that causes limited activity, paralysis, inability to control motion and is often accompanied by cognitive impairment or visual deficits. Children who experience cerebral palsy will definitely have limitations in the process of mobility. To help limitation of activity that occurs in children with cerebral palsy, ankle foot orthosis is used. Ankle foot orthosis is expected to help the patient in performing his activities at all times to give effect on the walking speed. In this research, actions performed by taking data before and after using dynamic ankle foot orthosis. Purpose of this research to determine the effect of the use of dynamic ankle foot orthosis on walking speed in children with cerebral palsy ". Methods: This type of research is quasi experimental pre and post test design. The subjects used were spastic cerebral palsy spherical patients in the Pediatric \& Neurodevelopmental Therapy Center (PNTC) who had determined the inclusion and exclusion criteria. Number of subjects 15 people. Result: This research is based on data analysis result that wilcoxon test value got $p=0,001(p<0,05)$. Conclusion: This result indicates that there is an effect of the use of ankle foot orthosis dynamic on road speed in children with cerebral palsy.
\end{abstract}

Keywords: ankle foot orthosis dynamic, cerebral palsy, walking speed.

\section{PENDAHULUAN}

Masa tumbuh kembang anak adalah periode yang sangat riskan bagi setiap kehidupan anak, sehingga perlu mendapat perhatian dari semua aspek yang mendukung maupun yang mempengaruhi pertumbuhan dan perkembangan anak. Berbagai penyakit/kelainan pada anak yang dapat berakibat terhadap pertumbuhan dan perkembangan adalah Cerebral palsy (CP). Cerebral Palsy adalah gangguan perkembangan yang diperkenalkan pertama kali oleh William Little pada tahun 1861 dan dikenal dengan Little's disease. Cerebral Palsy adalah sindroma postur dan gangguan motorik yang non progresif yang menyebabkan terbatasnya aktivitas dan seringkali disertai gangguan kognitif atau defisit visual. Hal itu disebabkan oleh adanya kerusakan otak nonprogresif atau disfungsi perkembangan otak pada saat janin maupun bayi. (Sitorus dkk, 2016)

Cerebral palsy ditandai dengan kerusakan motorik dan hadir bersamaan dengan disfungsi mental dan fisik. Cerebral palsy jika dilihat dari pengertiannya, cerebral artinya otak, palsy dapat berarti kelemahan atau kelumpuhan, atau ketidakmampuan melakukan kontrol gerakan. Otak mengontrol semua tindakan. Bagian otak yang berbeda-beda mengontrol gerakan 
pada masing-masing otot tubuh yang berbeda. Pada cerebral palsy, terjadi kerusakan atau adanya hambatan perkembangan pada salah satu area otak. (Bagnara 2000 dalam Valentina 2014)

Kasus Cerebral Palsy (CP) mengalami peningkatan cukup signifikan dan bervariasi di berbagai negara. Asosiasi CP dunia memperkirakan terdapat lebih dari 500.000 penderita di Amerika. 13 bayi dari 1000 kelahiran di Denmark, 5 dari 1000 kelahiran di Amerika Serikat. Di Indonesia, data penderita Cerebral Palsy belum diketahui secara pasti. Seribu kelahiran hidup di Indonesia, sekitar 2-2,5 persennya beresiko Cerebral Palsy. Di YPAC Surakarta, tercatat anak yang mengalami Cerebral Palsy terus meningkat. Pada tahun 2007 sebanyak 198 anak, tahun 2008 sebanyak 307 anak, tahun 2009 sebanyak 313 anak, tahun 2010 sebanyak 330 anak, dan 2011 sebanyak 343 anak. (Wulandari dkk, 2015)

Cerebral palsy bukan penyakit yang berdiri sendiri tetapi nama yang diberikan untuk variasi dari sindrom kerusakan saraf motorik yang terjadi sekunder dan menjadi lesi dalam perkembangan otak. Kerusakan otak bersifat permanen dan tidak dapat disembuhkan tetapi dampak dari $\mathrm{CP}$ dapat diperkecil. Etiologi $\mathrm{CP}$ dibagi menjadi tiga: Pranatal (Infeksi TORCH, keracunan, radiasi sinar $\mathrm{X})$, Natal (anoksia, perdarahan otak, prematur, ikterus), Postnatal (trauma kapitis, ensefalitis, meningitis dan luka parut pasca bedah). Faktor risiko terjadinya $\mathrm{CP}$ antara lain jenis kelamin, ras, genetik, sosioekonomi, riwayat obstetri, penyakit yang diderita ibu, primipara, malnutrisi, BBLR, skor APGAR. (Sitorus dkk, 2016)
Cerebral palsy ditandai dengan kerusakan motorik dan hadir bersamaan dengan disfungsi mental dan fisik. Cerebral palsy jika dilihat dari pengertiannya, cerebral artinya otak, palsy dapat berarti kelemahan atau kelumpuhan, atau ketidakmampuan melakukan kontrol gerakan. Otak mengontrol semua tindakan. Bagian otak yang berbeda-beda mengontrol gerakan pada masing-masing otot tubuh yang berbeda. Pada cerebral palsy, terjadi kerusakan atau adanya hambatan perkembangan pada salah satu area otak. Lebih jauh lagi dikatakan bahwa cerebral palsy merupakan sekelompok gangguan yang sifatnya permanen pada perkembangan gerakan dan postur yang menyebabkan keterbatasan aktivitas, yang tergolong pada gangguan non-progresif yang terjadi pada fase perkembangan otak fetus dan janin. Gangguan motorik pada cerebral palsy seringkali berdampak pada sensasi, persepsi, kognisi, komunikasi dan perilaku, dengan epilepsy dan masalah-masalah muskolouskeletal lainnya. Definisi ini telah mengikuti World Health Organization's Internationalization Classification of Functioning, Disability and Health. Anak-anak yang mengalami cerebral palsy akan mengalami permasalahan seperti kelemahan, kekakuan, kelambanan, dan mengalami masalah dengan keseimbangan. (Valentina, 2014)

Spastisitas adalah meningkatnya tonus otot secara mendadak ketika otot digerakan secara pasif atau direnggakan. Penderita cerebral palsy spastic akan merasakan kekakuan pada anggota geraknya karena aktivitas yang berlebihan (hyperactivity) yang dapat mengakibatkan limited movement. Normalnya, otot memilik tonus yang cukup untuk 
mempertahankan postur atau gerakan melawan gravitasi dan secara bersamaan menunjukkan fleksibilitas dan kecepatan pergerakan. (Ramadhan, 2016)

Spastisitas merupakan sebuah tantangan besar bagi rehabilitas anak cerebral palsy. Spastisitas dapat menghambat fungsi sendi, menimbulkan rasa sakit, mengganggu kualitas tidur, menyebabkan komplikasi dan cukup menyulitkan bagi para terapis. Permasalahan lain yang akan dialami oleh penderita spastisitas adalah kesulitan dalam menjalani aktivitas sehari-hari seperti gait, makan, mandi dan memakai pakaian. Jika spastisitas dibiarkan, akan menimbulkan permasalahan lain yang lebih kompleks, seperti nyeri otot atau spasme, kesulitan saat bangun dari tempat tidur dan transfers, posisi duduk yang tidak benar, ketidakseimbangan saat berdiri dan berjalan, kontraktur yang akan menyebabkan deformitas sendi dan tulang. (Ramadhan, 2016)

Pada anak, spastisitas memiliki keuntungan tersendiri, yaitu membantu tungkai untuk berada pada posisi ekstensi, sehingga dapat menyupport berat badan tubuh melawan gravitasi. Jika peningkatan tonus otot terjadi pada trunk extensors, anak dapat berdiri dan berjalan beberapa langkah. Pengaruh buruk spastisitas terhadap otot dan sendi pada anggota gerak tubuh menyebabkan pergerakan tidak normal dan menghambat pertumbuhan anak. Efek dari spastisitas, antara lain, (1) terhambatnya pergerakan, (2) terhambatnya pertumbuhan otot longitudinal, (3) terhambatnya sintesis protein pada sel-sel otot, (4) peregangan otot tidak maksimal pada aktivitas seharihari, dan (5) meningkatkan deformitas otot dan sendi. Efek yang muncul pada anggota gerak atas, yaitu elbow, wrist dan finger flexion. Efek pada anggota gerak bawah, yaitu hip flexion, adduksi thigh, knee flexion, equinovarus foot, dan hiperekstensi ibu jari. (Ramadhan, 2016)

Jalan merupakan salah satu cara dari ambulansi, pada manusia ini dilakukan dengan cara bipedal (dua kaki). Dengan cara ini jalan merupakan gerakan yang sangat stabil meskipun demikian pada kondisi normal jalan hanya membutuhkan sedikit kerja otot-otot tungkai . Pada gerakan ke depan sebenarnya yang memegang peranan penting adalah momentum dari tungkai itu sendiri atau akselerasi, kerja otot justru pada saat deselerasi. Berjalan adalah berpindahnya tubuh dari satu titik, ketitik berikutnya dengan cara menggunakan kedua tungkai (bipedal) : posisi tubuh selalu tegak selama proses berlangsung). Pola repetisi daripada penumpuan berat badan dari satu tungkai ketungkai yang lain dengan heel - toe striding adalah fenomena yang membedakan manusia dengan hominids yang lebih primitive. (Kalangi dkk, 2015)

Kecepatan adalah waktu yang digunakan untuk menempuh jarak tertentu. Untuk mengetahui berapa banyak kecepatan kita saat berjalan adalah dengan menghitung waktu yang dibutuhkan untuk perpindahan dibagi dengan jarak yang ditempuh. Sehingga dapat disimpulkan bahwa kecepatan berjalan adalah waktu yang digunakan untuk menempuh jarak tertentu pada saat berpindahnya tubuh dari satu titik, ketitik berikutnya dengan cara menggunakan kedua tungkai.

Kecepatan berjalan normal juga dipengaruhi beberapa faktor antara lain ; (1) panjang tungkai, orang yang memiliki tungkai panjang akan lebih jauh jangkauan langkahnya dibandingkan 
dengan yang tungkainya lebih pendek, kecepetan berjalan normal juga dipengaruhi beberapa faktor antara lain ; (1) panjang tungkai, orang yang memiliki tungkai panjang akan lebih jauh jangkauan langkahnya dibandingkan dengan yang tungkainya lebih pendek, (2) keseimbangan, apabila mengalami gangguan keseimbangan maka akan berpengaruh terhadap kecepatan berjalan, (3) kekuatan otot, orang yang mengalami penurunan kekuatan otot dalam berjalan akan mengalami penurunan dalam kecepatan berjalan, otot-otot tungkai yang berperan besar dalam berjalan yaitu otot plantar fleksor pergelangan kaki yang bekerja untuk mendorong kaki sehingga menimbulkan gaya dorong kedepan sedangkan otot-otot pada ekstensor lutut berperan sebagai stabilisasi pada saat menumpu. Faktor biomekanik berfungsi untuk stabilisasi pergerakan sendi dalam kecepatan berjalan. Stabilisasi mempengaruhi dalam kecepatan jalan, persendian dan biomekanik pada otot memiliki efek langsung terhadap kecepatan berjalan. (Pujakesuma, 2015)

Adapun faktor-faktor yang mempengaruhi gait dalam hal ini kecepatan berjalan antara lain umur, tinggi badan (berhubungan dengan panjang tungkai), kondisi muskuloskeletal, postur yang abnormal, ketidakstabilan, nyeri, kekakuan pada persendian hip, knee, ankle, kelemahan otot, keseimbangan, penyakit yang menyertai, dan penggunaan obat.

$$
\text { Menurut (Pujakesuma, 2015) }
$$

untuk mengukur kecepatan jalan seseorang dapat menggunakan rumus :

Keterangan :

$\mathrm{v}:$ kecepatan $(\mathrm{m} / \mathrm{s})$

$\mathrm{s}:$ jarak yang ditempuh (meter) $\mathrm{t}:$ waktu tempuh (sekon)

Beberapa hasil penelitian menyebutkan (1) menurut Sandra A Radtka et al 1997, penggunaan dynamic ankle-foot orthoses (DAFOs) with a plantar-flexion stop dan polypropylene solid ankle-foot orthoses (AFOs) saat berjalan dapat meningkatkan stride length (jarak antara dua jejak kaki, pada kaki yang sama) dan meningkatkan candance (jumlah langkah) dibandingkan tanpa memakai AFO, (2) menurut Mark F. Abel et al 1998, AFO dapat meningkatkan fungsi jalan pada anak CP, (3) menurut Jacqueline 2001, pada 12 anak CP hemiplegia penggunaan hinge AFO dapat meningkatkan step length (jarak kaki kontak dengan tanah dengan kaki lainnya) dan stride length (jarak antara dua jejak kaki, pada kaki yang sama) dan mengurangi energy yang dikelurkan, (4) menurut Hank White et al 2002, pada anak penderita cerebral palsy terdapat adanya peningkatan parameter gait pada penggunaan AFO dibandingakan berjalan tanpa alas, (5) menurut Cathleen E Buckon 2004, penggunaan AFO dapat meningkatkan kemampuan fungsional pada anak dengan spastic diplegia. (6) menurut Sandra A. Radtka et al 2005, bahwa solid dan hinge ankle foot orthosis meningkatkan stride length (jarak antara dua jejak kaki, pada kaki yang sama) dan pada saat ankle plantar flexor moment ke normal pada saat initial contact, midstance and terminal stance, (7) menurut Shlomo Hayek et al 2007, bahwa penggunaan AFO dapat memperbaiki parameter gait dan keseimbangan berjalan pada anak cerebral palsy spastic.

Ankle foot orthosis (AFO) adalah alat bantu orthopaedi berbentuk splint (menutupi sebagian area lesi/kecacatan) 
yang dipasangkan pada ankle foot. AFO berbentuk seperti kaki, fungsi utama dari Ankle foot orthosis (AFO), Adalah salah satu jenis alat penguat anggota gerak yang berfungsi untuk kondisi Flatt Foot, Genu Varus (pergelangan kaki "O"), genu Valgus (pergelangan kaki "X"), Drop Foot, Congenital Talipes Equino Varus (CTEV), koreksi kaki pada anak Cerebral palsy serta untuk membantu mobilitas pasien Drop foot pasca stroke, Genu Varus, Genu Valgus. AFO ini dibuat dari bahan polyetilene dan polypropilen. Alat bantu ini di desain dengan memperhatikan aspek patologis, biomekanis dan mekanis. (Pratomo, 2012)

Fungsi dari Ankle foot orthosis (AFO) yaitu : mengontrol pergerakan, mengoreksi alignment, Offload weight, mengakomodasi/ mencegah deformitas, dan menyediakan tekanan pada circumferensial. Jenis Ankle foot orthosis ada : Rigid AFO, Fleksible AFO dan Jointed AFO. Jenis jointed AFO memiliki trimline yang sama seperti AFO rigid namun terdapat penambahan joint pada bagian ankle. Terdapat mekanisme ankle joint yang mungkin digabungkan ke jointed AFO untuk membantu pergerakan pada 1 arah dan mencegah pergerakan ke arah lain. $A F O$ jointed biasanya menggunakan plantarfleksion stop pada posisi $90^{\circ}$. Jointed afo diberikan ketika memungkinkan gerakan passive dorsi fleksi. Jointed AFO umumnya di preskripsikan untuk pasien yang membutuhkan stabilitas subtalar tapi tidak membutuhkan kontrol dorsi fleksi dan plantar fleksi seperti pasien dengan spastisitas ringan atau pasien dengan hyperektensi knee (Orlandi et al, 2014).

AFO jenis ini memberikan kondisi yang lebih mendekati normal gait karena memungkinkan pergerakan dorsifleksi saat fase stance, hal ini juga membuat lebih mudah untuk berjalan pada area yang tidak rata dan juga pada tangga. Jenis ini pilihan yang terbaik pada pasien ambulasi. (berker dan yalcin, 2010)

Hasil studi pendahuluan di PNTC terdapat 30 anak penderita Cerebral Palsy, tiga anak dapat berjalan mandiri, 12 anak yang dapat berjalan dengan bantuan maupun tidak dengan bantuan, sembilan anak yang sudah dapat berjalan dengan walker maupun dengan bantuan orang tua, dan sisanya masih dalam proses latihan berdiri. Dan menurut beberapa orang tua anak penderita cerebral palsy mengatakan, (1) AFO (Ankle Foot Orthosis) digunakan hampir setiap saat, baik penderita $\mathrm{CP}$ yang mampu berjalan tanpa alat bantu hingga penderita yang menggunakan kursi roda, (2) orthosis sangat dibutuhkan dan selalu digunakan dalam proses terapi dalam jangka waktu yang lama, (3) orthosis digunakan tidak hanya di tempat terapi, tetapi juga digunakan dalam beraktivitas di rumah, (4) orthosis membantu penderita dalam melakukan kegiatannya setiap waktu, (5) dan kebanyakan penderita memiliki keinginan yang kuat untuk dapat berjalan, terlihat normal, dan dapat melakukan banyak hal secara mandiri.

Berdasarkan permasalahan yang dialami penderita $\mathrm{CP}$ dan hasil penelitian yang ada, penulis tertarik untuk dalam meneliti dan untuk mengetahui tentang pengaruh penggunaan Ankle Foot Orthosis Dinamis terhadap kecepatan jalan pada anak penderita Cerebral Palsy.

\section{METODE PENELITIAN}

Penelitian menggunakan rancangan quasi eksperimental pre and post test design. Desain pre dan post 
digunakan karena adanya penilaian sebelum diberikan intervensi dan penilaian ulang setelah diberikan intervensi, sehingga bisa dibandingkan selisih kecepatan berjalan antara sebelum dan sesudah intervensi. Pada penelitian ini sebelum dan setelah penggunaan Ankle Foot Orthosis (AFO) Dinamis akan dilakukan penilaian terhadap kecepatan berjalan pada anak penderita Cerebral palsy. Desain penelitian dapat digambarkan sebagai berikut:

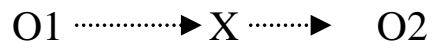

Gambar 1. Rancangan penelitian

Keterangan:

O1=Observasi awal

$\mathrm{O} 2=$ Observasi setelah pemakaian orthosis $\mathrm{X}=$ Perlakuan, yaitu memakaikan subjek dengan ankle foot orthosis dinamis

Penelitian dilaksanakan di Pediatric \& Neurodevelopmental Therapy Center (PNTC). Waktu yang dibutuhkan dalam penelitian ini bulan JanuariFebruari 2018. Populasi pada penelitian ini adalah anak penderita cerebral palsy di Pediatric \& Neurodevelopmental Therapy Center (PNTC) sebanyak 30 anak.

Sampel pada peneliti ini ditentukan menggunakan metode teknik purposive sampling. Menurut Nasution (2003) teknik purposive sampling adalah pengambilan sampel dilakukan hanya atas dasar pertimbangan penelitinya saja yang menganggap unsur-unsur yang dikehendaki telah ada dalam anggota sampel yang diambil.

Berdasarkan subjek yang memenuhi kriteria inklusi peneliti mendapatkan 15 sampel pada anak cerebral palsy di Pediatric \& Neurodevelopmental Therapy Center
(PNTC). Subjek penelitian diambil dari anak penderita cerebral palsy di PNTC. Dimana seluruh subjek dalam penelitian ini telah memenuhi kriteria sebagai berikut :

a. Kriteria Inklusi

Kriteria inklusi dalam penelitian ini yaitu : (1) Anak CP spastic yang sudah bisa berjalan, (2) Anak CP menggunakan AFO Dinamis, (3) Anak CP dengan tonus otot 0-2, (4) Anak CP dengan level GMFCS IIII dan (5) Anak CP usia 6-12 tahun

\section{b. Kriteria Eksklusi}

Kriteria inklusi dalam penelitian ini yaitu: (1) Anak CP yang belum bisa berjalan, (2) Anak CP dengan tonus otot 3-5, (3) Anak CP dengan level GMFCS IV-V dan (4) Anak CP usia kurang dari 6 tahun dan lebih dari 12 tahun

Pada penelitian ini menggunakan instrument stopwatch dan lintasan lurus sepanjang 10 meter atau 10-metre fast walk test $(10 \mathrm{mFWT})$. Peneliti berdiri pada garis start dan mengintruksikan pada anak untuk berjalan ketika siap, dan menyakinkan untuk sebisa mungkin berjalan cepat. Dan peneliti lainnya berdiri pada garis finish diluar tanda dan mengoperasi dengan stopwatch digital, dan merekam waktu yang dibutuhkan dalam berjalan $10 \mathrm{~m}$. Waktu dimulai ketika sampel mulai langkahnya dan berakhir ketika kaki melintasi garis finish. (Patricia, 2008). Penggunaan media stopwatch diharapkan akan secara langsung memperoleh waktu, dari jarak yang telat ditetapkan, kemudian dapat menghitung kecepatan dari jarak dan waktu yang telah diperoleh dengan penggunaan stopwatch. (Arifiyanto dan Purwanto, 2014)

Prosedur Penelitian meliputi dari :

\section{Tahap Persiapan}


Tahapan ini merupakan langkah awal sebelum melakukan proses penelitian dimana meliputi membuat surat perizinan dari pihak Politeknik Kesehatan Surakarta Jurusan Ortotik Prostetik secara tertulis, kemudian melalukan perizinan kepada pihak PNTC untuk melakukan penelitian dan mengadakan pendekatan kepada terapis untuk bisa membantu selama proses penelitian.

\section{Tahap Pelaksanaan}

a. Seleksi subjek penelitian

Diawali dengan mendata pasien apakah subjek masuk dalam kriteria inklusi, ekslusi. Dan kemudian bertanya apakah bersedia untuk menjadi subjek dalam penelitian, selanjutnya dijelaskan mengenai jalannya penelitian. Serta meminta subjek atau orangtua untuk mengisi dan menandatangani surat persetujuan (informed concent).

b. Pengambilan data saat subjek tidak memakai AFO

Pengambilan data awal meliputi pre test $\mathrm{O}_{1}$ dimulai pada saat subjek tidak menggunakan ankle foot orthosis dinamis. Pengambilan data dengan cara subjek diminta untuk berjalan melintasi lintasan sepanjang 10 meter dan dihitung waktu yang dibutuhkan saat berjalan

c. Pengambilan data saat subjek menggunakan AFO

Subjek memakai AFO setelah pengambilan data awal, dimana masingmasing subjek memakai alat berupa ankle foot orthosis dinamis. Pengambilan data post test $\mathrm{O}_{2}$ saat subjek memakai ankle foot orthosis dinamis dengan cara pasien diminta untuk berjalan melintasi lintasan sepanjang 10 meter dan dihitung waktu yang dibutuhkan saat berjalan.

d. Pengolahan data
Setelah data penelitian terkumpul baik melalui pre test $\mathrm{O}_{1}$ dan post test $\mathrm{O}_{2}$, selanjutnya dilakukan edit dan entry data.

Metode pengolahan dan analisis data yaitu dengan menganalisa data yang telah terkumpul melalui 3 tahap yaitu : (1) Penyuntingan (Editing) dalam tahap ini dilakukan pengambilan data berupa pengukuran menggunakan stopwatch, (2) Pengkodean (Coding), pemberian kode dimaksudkan untuk mempermudah dalam pengolahan data dan proses selanjutnya melalui tindakan pengklarifikasian data dan (3) Tabulasi (Tabulating), yaitu asil pengkodean dimasukan dalam tabel, yang dilakukan secara manual. Data yang telah ditabulasi kemudian dianalisis dengan bantuan program komputer. Program yang dipakai dalam pengolahan dan analisis data ini adalah software IBM SPSS for windows.

Uji prasyarat dalam penelitian ini yaitu uji prasyarat untuk menentukan uji hipotesis. Uji prasyarat yang dibutuhkan untuk menentukan uji Hipotesis yaitu uji normalitas. Jika jumlah data lebih dari 50 maka digunakan uji kolmogorov-smirnov dan uji shapiro-wilk apabila data kurang dari 50. Apabila distribusi data normal maka menggunakan uji parametrik dan jika data tidak normal menggunakan uji non parametrik. Dasar pengambilan kesimpulan berdasarkan pada nilai probabilitas $(\mathrm{p})>0,05$.

\section{HASIL PENELITIAN}

Subjek dalam penelitian ini adalah anak cerebral palsy di Pediatric \& Neurodevelopmental Therapy Center (PNTC) dalam kurun waktu Januari Februari 2018 yang berjumlah 15 orang . Tujuan dari penelitian ini untuk mengetahui pengaruh penggunaan Ankle Foot Orthosis Dinamis terhadap 
kecepatan berjalan pada anak penderita Cerebral Palsy. Dalam mengukur kecepatan berjalan digunakan rumus yaitu $\mathrm{V}=\mathrm{s} / \mathrm{t}$, dengan catatan $\mathrm{s}$ adalah jarak tempuh (meter), dan $\mathrm{t}$ adalah waktu tempuh (sekon), dengan jarak tempuh sepanjang 10 meter atau 10-metre fast walk test $(10 \mathrm{mFWT})$. Hasil penelitian akan menjelaskan mengenai pengaruh pengaruh penggunaan Ankle Foot Orthosis Dinamis terhadap kecepatan berjalan pada anak penderita Cerebral Palsy. Dari hasil penelitian ini akan dijelaskan karakteristik subjek, variabel dan uji hipotesis dalam menjawab rumusan masalah.

a. Karakteristik subjek

Sebelum melakukan uji hipotesis, terlebih dahulu akan dipaparkan mengenai karakteristik subjek untuk mengetahui gambaran umum tentang subjek yang dijadikan sampel dalam penelitian. Karakteristik subjek ini meliputi jenis kelamin, umur, derajat spastisitas dan level GMFCS (Gross Motor Functional Classification System). Jumlah subjek dalam peneitian ini yaitu 15 orang.

1) Karakteristik subjek berdasarkan jenis kelamin

Berdasarkan karakteristik jenis kelamin, tampak bahwa subjek tidak hanya berasal dari gender tertentu. Hal ini ditunjukkan pada Tabel 1. berikut ini :

Tabel 1. Distribusi Subjek Berdasarkan Jenis Kelamin

\begin{tabular}{lcccc}
\hline Jenis & N & \multicolumn{2}{c}{ Mean } & $\begin{array}{c}\text { Persentase } \\
\text { Kelamin }\end{array}$ \\
\cline { 3 - 4 } & & Pre & Post & \\
\hline Laki-laki & 8 & 0.1687 & 0.2238 & $53,3 \%$ \\
Perempuan & 7 & 0.1571 & 0.2086 & $46,7 \%$ \\
\hline Total & $\mathbf{1 5}$ & $\mathbf{0 . 1 6 3 3}$ & $\mathbf{0 . 2 1 6 7}$ & $\mathbf{1 0 0 , 0 \%}$ \\
\hline Sumber : Data & primer & diolah 2018
\end{tabular}

Tabel 1. menunjukan distribusi frekuensi karakteristik sampel berdasarkan jenis kelamin. Jumlah sampel laki-laki lebih banyak yaitu 8 sampel $(53,3 \%)$ dan perempuan 7 sampel (46,7\%). Perbedaan jumlah sampel yang didapatkan dalam penelitian ini tidak begitu jauh yaitu hanya selisih 1 sampel.

2) Karakteristik subjek berdasarkan umur

Berdasarkan data yang diperoleh diketahui bahwa umur subjek berkisar antara 6 tahun sampai 12 tahun. Hal ini ditunjukkan pada Tabel 2. berikut ini :

Tabel 2. Distribusi Subjek Berdasarkan Umur

\begin{tabular}{ccccc}
\hline & & \multicolumn{2}{c}{ Mean } & Persentase \\
\cline { 3 - 4 } Umur & N & Pre & Post & $(\mathbf{1 0 0 \% )}$ \\
\hline 6 & 1 & 0.800 & 0.1000 & $6,7 \%$ \\
7 & 3 & 0.2367 & 2.2867 & $20 \%$ \\
8 & 4 & 0.1525 & 0.2225 & $26,7 \%$ \\
9 & 5 & 0.1900 & 0.2340 & $33,3 \%$ \\
12 & 2 & 0.2000 & 0.2650 & $13,3 \%$ \\
\hline Total & $\mathbf{1 5}$ & $\mathbf{0 . 1 6 3 3}$ & $\mathbf{0 . 2 1 6 7}$ & $\mathbf{1 0 0 . 0 \%}$ \\
\hline
\end{tabular}

Sumber: Data primer diolah 2018

Berdasarkan karakteristik umur, dari 15 jumlah sampel pada anak cerebral palsy distribusi jumlah sampel terbanyak pada umur 9 tahun yaitu sebanyak 5 sampel $(33,3 \%)$, diikuti umur 8 tahun yaitu sebanyak 4 sampel (26,7\%), kemudian umur 7 tahun sebanyak 3 sampel (20\%), selanjutnya umur 12 tahun yaitu 2 sampel $(13,3 \%)$, dan terakhir umur 6 tahun sebanyak 1 sampel $(6,7 \%)$.

3) Karakteristik subjek berdasarkan derajat spastisitas

Berdasarkan data yang diperoleh diketahui bahwa derajat spastisitas subjek dilihat dari skala asworth. Hal ini ditunjukkan pada Tabel 3. berikut ini : 
Tabel 3. Distribusi Subjek Berdasarkan Derajat Spastisitas

\begin{tabular}{|c|c|c|c|c|}
\hline \multirow{2}{*}{$\begin{array}{l}\text { Derajat } \\
\text { spastisitas }\end{array}$} & \multirow[t]{2}{*}{$\mathbf{N}$} & \multicolumn{2}{|l|}{ Mean } & \multirow{2}{*}{$\begin{array}{l}\text { Persentase } \\
(100 \%)\end{array}$} \\
\hline & & Pre & Post & \\
\hline 1 & 5 & 0.1880 & 0.2420 & $33.7 \%$ \\
\hline 2 & 10 & 0.1510 & 0.2040 & $66,3 \%$ \\
\hline Jumlah & 15 & 0.1633 & 0.2167 & $100.0 \%$ \\
\hline
\end{tabular}

Sumber: Data primer diolah 2018

Dari hasil karakteristik derajat spastisitas diketahui hanya terdapat 2 grade, yaitu grade 1 sebanyak 5 subjek $(33,7 \%)$ dan grade 2 sebanyak 10 subjek $(66,3 \%)$.

4) Karakteristik subjek berdasarkan level GMFCS (Gross Motor Functional Classification System)

Berdasarkan data yang diperoleh diketahui bahwa level GMFCS (Gross Motor Functional Classification System) dapat dilihat dari Tabel 4. sebagai berikut

Tabel 4. Distribusi Subjek Berdasarkan Level GMFCS

\begin{tabular}{|c|c|c|c|c|}
\hline \multirow{2}{*}{$\begin{array}{l}\text { Level } \\
\text { GMFCS }\end{array}$} & \multirow[t]{2}{*}{$\mathbf{N}$} & \multicolumn{2}{|c|}{ Mean } & \multirow{2}{*}{$\begin{array}{c}\text { Persentase } \\
(\mathbf{1 0 0 \%})\end{array}$} \\
\hline & & Pre & Post & \\
\hline 1 & 1 & 0.2600 & 0.3000 & $6,7 \%$ \\
\hline 2 & 13 & 0.1623 & 0.2192 & $86,7 \%$ \\
\hline 3 & 1 & 0.0800 & 0.1000 & $6,7 \%$ \\
\hline Total & 15 & 0.1633 & 0.2167 & 100.0 \\
\hline
\end{tabular}

berdasarkan karakteristik level GMFCS

(Gross Motor Functional Classification System) diketahui bahwa kemampuan mobilitas dan keterbatasan aktivitas subjek hanya terdiri dari tiga level. Level GMFCS (Gross Motor Functional Classification System) terbanyak yaitu level 2 sebanyak 13 subjek $(86,7 \%)$ dan dua level lainnya yaitu level 1 dan 3 hanya terdiri dari masing-masing 1 subjek $(6,7 \%)$. Berdasarkan data diketahui ada perbedaan level GMFCS (Gross Motor Functional Classification System) yang sukup besar.

Analisis data yang digunakan untuk mengetahui pengaruh penggunaan Ankle Foot Orthosis Dinamis terhadap kecepatan berjalan pada anak penderita Cerebral palsy yaitu menggunakan uji $\mathrm{T}$ berpasangan apabila data berdistribusi normal dan menggunakan wilcoxon apabila data berdistribusi tidak normal. Variabel bebas adalah pengguna Ankle Foot Orthosis Dinamis sedangkan variabel terikatnya adalah kecepatan jalan pada anak penderita Cerebral palsy yang mempunyai skala data rasio. Uji komparatif ini dimaksudkan untuk menguji ada tidaknya perbedaan yang signifikan antara nilai variabel sebelum (kecepatan jalan saat subjek tidak memakai ankle foot orthosis dinamis) dan sesudah diberi intervensi (kecepatan berjalan saat subjek menggunakan ankle foot orthosis dinamis).

Pengujian hipotesis dilakukan agar dapat diketahui kesesuaian antara hipotesis yang telah dirumuskan dengan hasil data yang di dapat dari penelitian. Untuk menguji hipotesis tersebutdapat digunakan bantuan program perhitungan SPSS (Statistical Product and Service Solution) versi 17.

a. Uji Prasyarat

Uji prasyarat dalam penelitian ini yaitu uji prasyarat untuk menentukan uji hipotesis. Uji prasyarat yang dibutuhkan untuk menentukan uji Hipotesis yaitu uji normalitas. Jika jumlah data lebih dari 50 maka digunakan uji kolmogorov-smirnov dan uji shapiro-wilk apabila data kurang dari 50. Apabila distribusi data normal maka menggunakan uji parametrik dan jika data tidak normal menggunakan uji non parametrik. Dasar pengambilan 
kesimpulan berdasarkan pada nilai probabilitas $(\mathrm{p})>0,05$.

1) Uji normalitas

Uji normalitas ini dimaksudkan untuk mengetahui sebaran data dari kedua kelompok variabel yaitu penggunaan ankle foot orthosis dinamis dan kecepatan berjalan. Uji normalitas dapat dilihat dari Tabel 5. berikut ini :

Tabel 5. Uji Normalitas Data

\begin{tabular}{llll}
\hline \multicolumn{4}{c}{ Shapiro-Wilk } \\
\hline & Statistic & df & Sig. \\
\hline Pre test & .944 & 15 & .430 \\
Post test & .874 & 15 & .039 \\
\hline
\end{tabular}

Sumber : Data primer diolah 2018

Pada hasil Tabel di atas, karena jumlah sampel 15 (< 50) maka menggunakan uji test of normality Shapiro-Wilk. Diperoleh nilai signifikansi 0,430 pada skor pre test dan nilai signifikansi 0,039 pada skor post test. Karena nilai signifikasi kelompok pre test (p) > 0,05 maka dapat diambil kesimpulan bahwa sebaran data normal. Sedangkan pada kelompok post test nilai signifikasi $(\mathrm{p})<0,05$ yang berarti bahwa sebaran data tidak normal. Karena hasil dari salah satu kelompok variabel memiliki sebaran data yang tidak normal diputuskan untuk menggunakan uji non parametrik yaitu uji wilcoxon.

b. Uji Hipotesis

Uji hipotesis yang digunakan untuk mengetahui pengaruh penggunaan ankle foot orthosis dinamis terhadap kecepatan jalan pada anak penderita cerebral palsy yaitu menggunakan uji wilcoxon. Uji wilcoxon ini dimaksudkan untuk ada tidaknya perbedaan yang signifikan antara nilai variabel sebelum (kecepatan jalan saat subjek tidak memakai ankle foot orthosis dinamis) dan sesudah diberi intervensi (kecepatan berjalan saat subjek menggunakan ankle foot orthosis dinamis). Uji pengaruh dapat dilihat dari Tabel 6. sebagai berikut :

Tabel 6. Hasil Uji Wilcoxon

\begin{tabular}{lccc}
\hline & $\begin{array}{c}\text { Jumlah } \\
(\mathbf{n})\end{array}$ & Mean & $\boldsymbol{P}$ \\
\hline $\begin{array}{l}\text { Hasil } \\
\text { Pre } \\
\text { test }\end{array}$ & 15 & $0.1633 \pm 0.04499$ & \\
\hline $\begin{array}{l}\text { Hasil } \\
\text { Post } \\
\text { test }\end{array}$ & 15 & $0.2167 \pm 0.04577$ & 0.001 \\
\hline
\end{tabular}

Sumber : Data Primer diolah 2018

Berdasarkan hasil uji hipotesis menunjukan bahwa nilai signifikansi (p) $=0.001$, artinya nilai signifikansi $(\mathrm{p})<$ 0,05. Dengan demikian dapat disimpulkan bahwa hipotesis diterima atau ada pengaruh penggunaan ankle foot orthosis dinamis terhadap kecepatan jalan pada anak penderita cerebral palsy.

\section{PEMBAHASAN}

Tujuan penelitian ini adalah untuk menganalisis pengaruh penggunaan ankle foot orthosis dinamis terhadap kecepatan berjalan pada anak penderita cerebral palsy. Dengan mempertimbangkan jenis kelamin, umur, spastisitas dan level GMFCS (Gross Motor Functional Classification System) sehingga dapat melihat kecepatan berjalan pada anak penderita cerebral palsy.

1. Hasil analisa data karakteristik subjek terhadap kecepatan berjalan

a. Jenis Kelamin

Dari hasil analisa data karakteristik subjek berdasarkan jenis kelamin didapatkan hasil bahwa terlihat peningkatan nilai mean baik pada perempuan maupun laki-laki. Pada kelompok perempuan nilai mean pre test 0.1571 naik menjadi 0.2086 pada saat 
post test. Sedangkan kelompok laki-laki nilai mean pre test 0.1687 naik menjadi 0.2238 . Hasil diatas sejalan dengan hasil penelitian yang dilakukan oleh Artaria (2010) yang menyebutkan bahwa lakilaki lebih cepat bertumbuh daripada perempuan. Pernyataan ini berkaitan dengan penelitian yang dilakukan oleh Sorongan yang menyebutkan bahwa panjang tungkai berpengaruh terhadap kecepatan berjalan. Studi yang dilakukan Kerrigan menambahkan bahwa adanya perbedaan gait yang berhubungan dengan jenis kelamin diduga juga karena faktor anatomi, tinggi badan, maupun panjang kaki dimana perempuan lebih pendek daripada laki-laki. Sehingga dapat dikatakan bahwa nilai mean kelompok perempuan yang lebih rendah dipengaruhi karena anatomi tubuh anak perempuan yang cenderung lebih kecil dan panjang tungkai yang cenderung lebih pendek.

b. Umur

Dari hasil analisa data karakteristik subjek berdasarkan umur didapatkan hasil bahwa terlihat peningkatan nilai mean baik pada kelompok pre test maupun kelompok post test. Pada kelompok umur 6 tahun nilai mean pre test meningkat dari 0.0800 menjadi 0.1000 pada saat post test. Pada kelompok umur 7 tahun nilai mean pre test meningkat dari 0.1367 menjadi 0.1867 pada saat post test. Lalu pada kelompok umur 8 tahun nilai mean pre test meningkat dari 0.1525 menjadi 0.2225 pada saat post test. Peningkatan juga terlihat pada kelompok umur 9 tahun, yaitu nilai mean pretest dari 0.1900 menjadi 0.2340 pada saat post test. Terakhir pada kelompok umur 12 tahun nilai mean pre test meningkat dari 0.2000 menjadi 0.2650 pada saat post test. Hasil diatas sejalan dengan penelitian Permatasari (2017) yang menyebutkan bahwa gait semakin berkembang seiring bertambahnya umur. Pada anak peningkatan kecepatan berjalan yang dipengaruhi faktor umur berhubungan dengan berkembangnya kekuatan otot quadriceps, m. Plantar flexors, dan hip flexor, range of motion, dan oxygen uptake.

\section{c. Spastisitas}

Dari hasil analisa data karakteristik subjek berdasarkan spastisitas didapatkan hasil bahwa derajat spastisitas berbanding terbalik dengan kecepatan berjalan pada pre test maupun post test. Semakin rendah derajat spastisitas maka kecepatan berjalan akan semakin meningkat. Diketahui bahwa derajat spastisitas 1 memiliki nilai mean 0.1880 pada saat pre test dan meningkat menjadi 0.2420 pada saat post test. Sedangkan pada derajat spastisitas 2 diketahui nilai mean pre test adalah 0.1510 dan meningkat pada saat post test menjadi 0.2040. Hasil ini diperkuat dengan pernyataan Ramadhan (2016) yang menyatakan bahwa pengaruh buruk spastisitas terhadap otot dan sendi pada anggota gerak tubuh menyebabkan pergerakan tidak normal dan menghambat pertumbuhan.

d. Level GMFCS (Gross Motor Functional Classification System)

Dari hasil analisa data karakteristik subjek berdasarkan level GMFCS (Gross Motor Functional Classification System) didapatkan hasil bahwa level GMFCS (Gross Motor Functional Classification System) berbanding lurus dengan kecepatan berjalan pada pre test maupun post test. Semakin tinggi level GMFCS (Gross Motor Functional Classification System) maka kecepatan berjalan akan semakin meningkat. Diketahui bahwa level GMFCS 1 memiliki nilai mean 0.2600 pada saat pre test dan meningkat 
menjadi 0.3000 pada saat post test. Sedangkan pada level GMFCS 2 diketahui nilai mean pre test adalah 0.1623 dan meningkat pada saat post test menjadi 0.2192. Dan pada level GMFCS 3 nilai mean pre test adalah 0.800 dan meningkat pada saat post test menjadi 0.1000. Hasil ini diperkuat dengan pernyataan Febriarto (2017) level tertinggi GMFCS (Gross Motor Functional Classification System) untuk menggambarkan mobilitas adalah pada umur 6-12 tahun, dimana pada level ini anak sudah bisa berjalan tanpa hambatan sedangkan pada level terendah mobilisasi mandiri anak sangat terbatas walaupun menggunakan alat bantu.

2. Hasil analisis hipotesis data penelitian pengaruh penggunaan ankle foot orthosis dinamis terhadap kecepatan jalan

Hasil analisis hipotesis data penelitian menunjukkan perolehan nilai signifikansi (p) 0,001. Nilai signifikansi $<0,05$ yang berarti hal tersebut menunjukkan ada pengaruh yang signifikan antara penggunaan ankle foot orthosis dinamis terhadap kecepatan jalan pada anak penderita cerebral palsy.

Selain melihat dari hasil analisis nilai signifikansi (p) bisa juga melihat dari nilai perolehan mean. Pada Tabel 4.6 terlihat peningkatan nilai mean dari $0.1633 \pm 0.04499$ pada saat pre test menjadi $0.2167 \pm 0.04577$ pada saat post test. Hal ini menunjukkan bahwa kecepatan berjalan pada anak penderita cerebral palsy saat tidak memakai ankle foot orthosis dinamis lebih rendah dibandingkan dengan kecepatan berjalan pada anak penderita cerebral palsy saat menggunakan ankle foot orthosis dinamis. Dalam hal ini penggunaan ankle foot orthosis dinamis berpengaruh sangat signifikan dalam meningkatkan kecepatan berjalan pada anak penderita cerebral palsy.

Hasil penelitian yang menunjukan peningkatan kecepatan berjalan yang bermakna pada kelompok intervensi sesuai dengan penelitian Cathlee $\mathrm{n}$ et al, Jacqueline $\mathrm{R}$, serta Hank White et al (2002), bahwa gait parameter dan kemampuan fungsional pada anak cerebral palsy pengguna ankle foot orthosis dinamis dibandingkan yang berjalan tanpa alas. Dan penggunaan hinge $A F O$ dapat meningkatkan step length (jarak kaki kontak dengan tanah dengan kaki lainnya) dan stride length (jarak antara dua jejak kaki, pada kaki yang sama) dan mengurangi energy yang dikeluarkan

Berjalan merupakan hal penting yang dilakukan manumur setiap hari. Menurut Kalangi dkk (2015) berjalan merupakan salah satu cara ambulasi yang dilakukan dengan cara bipedal. Pada anak cerebral palsy memiliki keterbatasan fungsi gerak yang diakibatkan oleh terganggunya saraf sensorik sehingga anak tersebut sulit melakukan kegiatan sehari-hari termasuk kondisi yang menujukan untuk susah payah berjalan.

Ankle foot orthosis dinamis yang digunakan dalam penelitian ini dengan dengan tipe joint plantar flexionstop (PFS) dan berbahan plastik polyetiline dengan ankle joint dibagian malleolus medial dan lateral. Ankle foot orthosis dinamis berfungsi untuk mengontrol pergerakan joint dan alignment pada foot. Selain itu penggunaan Ankle foot orthosis dinamis plantar flexionstop (PFS) bertujuan untuk memfasilitasi atau meningkatkan fungsi gerak. Strap digunakan unutk mengunci tungkai dalam 
posisi koreksi dan fiksasi. Aplikasi three point pressure pada ankle foot orthosis dinamis plantar flexionstop (PFS) juga menyebabkan GRF jatuh didepan knee saat stance phase. Dengan adanya mekanisme kerja tersebut dapat membantu normalisasi dari spastisitas otot yang menurut Niamah (2017) dapat meningkatkan kecepatan berjalan.

\section{KESIMPULAN DAN SARAN}

Berdasarkan penelitian didapatkan hasil penelitian yang bermakna pada pengaruh penggunaan ankle foot orthosis dinamis terhadap kecepatan berjalan pada anak penderita cerebral palsy. Dari hasil uji hipotesis dengan uji wilcoxon didapatkn nilai p 0.001 artinya nilai signifikansi $(\mathrm{p})<0,005$ dengan hasil nilai mean pre test $0.1633 \pm 0.04499$ dan hasil mean post test $0.2167 \pm 0.04577$. Dimana nilai mean pre test dan post test terdapat selisih 0.0534. Hal ini menunjukan bahwa terdapat pengaruh yang signifikan penggunaan ankle foot orthosis dinamis terhadap kecepatan jalan pada anak penderita cerebral palsy. Dengan demikian dapat disimpulkan bahwa hipotesis diterima atau ada pengaruh penggunaan ankle foot orthosis dinamis terhadap kecepatan jalan pada anak penderita cerebral palsy.

Berdasarkan hasil penelitian ini, maka penelitian selanjutnya disarankan untuk mencari subjek penelitian yang lebih banyak seperti ditempat yang memiliki banyak pasien anak cerebral palsy tipe spastic, menambah waktu untuk proses penelitian agar data yang diperoleh lebih banyak, memberikan edukasi kepada orang tua subjek dalam pemakaian ankle foot orthosis dinamis disaat aktivitas sehari-hari, mengontrol seluruh kegiatan terapi yang dilakukan oleh subjek, dan melakukan penelitian di track yang sama dari satu subjek dengan subjek lainnya.

\section{DAFTAR RUJUKAN}

Anggraini, S., 2010; Efektivitas Penggunaan Metode Gleen Doman Dalam Bentuk Flashcard Terhadap Peningkatan Kemampuan Membaca Anak Cerebral Palsy Di SLB D YPAC Surakarta Tahun Ajaran 2009/2010. Universitas Sebelas Maret, Surakarta, 23-28.

Arifiyanto, Z. Purwanto., 2014; Penggunaan Media Stop Watch Untuk Meningkatkan Hasil Belajar Matematika Pada Siswa Kelas V Sekolah Dasar. JPGSD. Volume 02 Nomer 03 Tahun 2014.

Artaria, M., 2010; Perbedaan antara Lakilaki dan Perempuan: Penelitian Antropometris pada Anak-Anak Umur 6-19 Tahun. Departemen Antropologi, Universitas Airlangga, Surabaya. Jurnal Masyarakat Kebudayaan dan Politik Tahun 22, Nomor 4: 343349

Cathleen, E B., 2004; Comparison of three ankle-foot orthosis configuration for children with spastic diplegia. USA : Department, shriners hospitals for children. Developmetal Medicine \& Child neurology 2004, 46:590598

CSPO., 1998; Lower Extremity Orthotics Manual Foot/Ankle Orthotics (FO/AFO). Phnom Penh, hal 31

Djarwanto, P S. Pangestu, S., 1993; Statistik Induktif BPFEE. Yogyakarta 
Febriarto, d., 2017; Pengaruh Predictive Factor Terhadap Outcome Semls Pada Cerebral Palsy Spastic Diplegic di RS Orthopedi Prof. Dr.dr.R.Soeharso Surakarta. Surakarta. Program studi magister kedokteran keluarga minat utama biomedik program pascasarjana universitas sebelas maret

Hank,W. Jennifer, J. William, P. Chester, T. Janet, W., 2002; Clinically prescribed orthoses demonstrate an increase in velocity of gait in children with cerebral palsy: a retrospective study. Developmental Medicine and Child Neurology. 2002; 44(4):227-232.

Jacqueline, R. Reinald Brunner,.2001; Comparison of a dynamic and a hinged ankle-foot orthosis by gait analysis in patients with hemiplegic cerebral palsy. Gait and Posture 15 (2002) 18-24

JSPO., 2013; Ankle Foot Orthosis. Jakarta : Jakarta School Prosthetic and Orthotic, Jakarta, hal 3-44.

Kalangi, P. Angliadi, E. Gessal, J., 2015; Perbandingan Kecepatan Berjalan Pada Pasien Nyeri Punggung Bawah Subakut dan Kronik Menggunakan Time Up and Go Test. Jurnal e-Clinic (eCl), Volume 3, Nomor 1, Januari-April 2015.

Mark, F. Gregory, A. Christopher, L.Diane, L., 1998; Gait assessment of fixed ankle-foot orthoses in children with spastic diplegia. Archives of Physical Medicine and Rehabilitation; 1998; 79(2):126- 133.

Morris, M., 2002; Orthotic Management of Children with Cerebral Palsy.
JPO Journal of Prosthetics and Orthotics. Volume $14 \cdot$ Number 4 - 2002

Nasution, R., 2003; Teknik Sampling. Universitas Sumatera Utara 2003 Digitized by USU digital library

Ni'amah, S., 2017; Desain Orthosis Untuk Penderita Cerebral Palsy Spastik Dengan Konsep Easy To Use, Lightweight, Dan Social Confident. Institut Teknologi Sepuluh Nopember, Surabaya, 36.

Orlandi, C et al., 2010; Ankle foot orthosis. Univesity of the east ramon magsasay memorial medical center.

Patricia Thompson, dkk., 2008; Testretest reliability of the 10-metre fast walk test and 6-minute walk test in ambulatory school-aged children with cerebral palsy. Developmental Medicine \& Child Neurology 2008, 50: 370-376

Permatasari, G., 2017; Analisis Perbedaan Pengaruh Sepatu Berhak Wedge Dan Non-Wedge Terhadap Gait Dan Keseimbangan. Semarang. Program pendidikan sarjana kedokteran fakultas kedokteran Universitas diponegoro

Pratomo, R., 2012; Ankle Foot OrthosisAFO. Diakses tanggal 24/12/2017, Available from: http://areliamedica.blogspot.co.id/ 2012/05/ankle-foot-orthosisafo .html

Pudjiastuti, S. Rachmat, N. Ningsih, C., 2012; Perbandingan Fungsional AFo Solid dan AFO Artikulasi Selama Berjalan Pada Anak Cerebral Palsy. Jurnal Terpadu 
Ilmu Kesehatan, Jilid 2, November 2012, hlm. 1-94.

Pujakesuma, A., 2015; Pengaruh Panjang stump Terhadap Kecepatan Jalan Pasien Transtibial. Politeknik Kesehatan Surakarta, Surakarta, 34-35.

Ramadhan, K W., 2016; Pengaruh Penggunaan Ankle Foot Orthosis Static terhadap Derajat Spastisitas pada Anak Cerebra Palsy Hemiplegia. Politeknik Kesehatan Surakarta, Surakarta, 13-16.

Ramadhani, A., 2012; Keefektifan Pendekatan Brain Based Learning Terhadap Peningkatan Prestasi Belajar Ipa Pada Siswa Cerebral Palsy Kelas VI Di SLB N 1 Bantul. Universitas Negeri Yogyakarta, Yogyakarta, 12-13.

Ridgewell, E., 2011; The effect of sagittal plane ankle-foot orthosis alignment on gait inchildren with cerebral palsy. School of Human Biosciences Faculty of Health Sciences La Trobe University Bundoora, Victoria, Australia.

Sandra, A. Stephen, R. Danielle, M. Elise, J., 1997; Comparison of Gait with Solid, Dynamic, and No Ankle-Foot Orthoses in Children With Spastic Cerebral Palsy. Journal of American Physicaltherapy Association. 1997; 77(4):352-353

Sandra, A.Stephen, R. M, Elise., 2005; A comparison of gait with solid and hinged ankle-foot orthoses in children with spastic diplegic cerebral palsy. Gait and Posture. 2005; 21(3):303-310.

Shlomo, H, dkk., 2007; The effect of community-prescribed ankle-foot orthoses on gait parameters in children with spastic cerebral palsy. Journal Of Children's Orthopaedics. 2007; 1(6):325-332.

Sitorus, F. Mogi, T. Gessal, J., 2016; Prevalensi Anak Cerebral Palsy di Instalasi Rehabilitasi Medik RSUP Prof. DR.R.D.Kandou Manado Periode 2015. Jurnal KEDOKTERAN KLINIK (JKK), Volume 1 No 1, Desember 2016.

Sugiyono., 2011; Metode Penelitian Kuantitatif Kualitatif dan R\& D. Bandung : Afabeta

Waluyo, T S., 2010; Pengaruh Mobilisasi Trunk Terhadap Penurunan Spastisitas Pada Cerebral Palsy Spastik Diplegi. Jurnal Pena, Vol 19 No. 1, September 2010

Valentina, T., 2014; Penyesuaian Psikologis Orangtua Dengan Anak Cerebral Palsy. Psikologi Tahun 2014, Vol. 9, No. 2, hal. 57-64.

Wulandari, R. Weta. I W. Imron, M A., 2015; Penambahan Latihan Hidroterapi Pada Terapi Bobath Lebih Meningkatkan Kecepatan Berjalan Pada Cerebral Palsy Spastik Diplegi. Magister Program of Sport Physiology Udayana University.

Yanuar, I., 2012; Analisa gait (berjalan) Physiotherapy Care. Diakses tanggal 8/12/2017 http://physiotherapycare.blogspot. com/2012/06/analisagaitberjalan.html 